\begin{tabular}{cc}
\hline & International Journal of Engineering \&Technology, $7(3.12)(2018) 14-18$ \\
SPC & International Journal of Engineering \& Technology \\
Website: www.sciencepubco.com/index.php/IJET & Research paper \\
\hline
\end{tabular}

\title{
Performance Analysis of Single and Multiple Channel FSO System under Turbulent Conditions Using Various Models
}

\author{
A. Sree Madhuri ${ }^{1}$, M. Venkata Narayana ${ }^{2}$, Govardhani.Immadi ${ }^{3}$ \\ Department of ECE, Koneru Lakshmaiah Education Foundation, Vaddeswaram, Guntur, A.P, India \\ *Corresponding Author Email: ' asreemadhuri@kluniversity.in
}

\begin{abstract}
Telecommunications occupying the major part of research across the world, has become a part and parcel of present day human's life. As a part of research many new technologies emerged among which free space optics was found to be highly efficient and a competent technology. So, replacing the present microwave communications, in future free space optics provides many advantages like higher bandwidth, higher data rate (capable of sending up to $1.25 \mathrm{Gbps}$ of data, voice, and video communications simultaneously through the air), low bit error rate and license free long-range communications etc. As a known fact that every coin has two sides, free space optics besides providing the above advantages also suffers from many range limiting factors like fog, beam dispersion, atmospheric absorption, rain attenuation, snow, terrestrial scintillation amongst which rain, scintillation and fog are popular in tropical regions like India. In this paper the effect of rain on FSO link is analysed in 1/1 and 4/4 channel cases and the results were analysed.
\end{abstract}

Keywords: Telecommunications, bandwidth, rain, fog, channel, tropical region, free space optics.

\section{Introduction}

Free space optics is a perfect line of sight communication where the carrier which supports the communication makes it unique and an efficient technology that provides high quality and uninterrupted transmission [1]. The carrier used here is of the order of Tera Hertz which can carry large data and can reach the destination with the speed of light. These two major qualities make free space optics profitable to the field of communication. Free space optics follows the same mechanism of the conventional communication systems where the difference lies only in the carrier which is an optical signal (light) [2]. As the signal travels in the free space to reach the receiver it encounters many obstacles that interrupt their natural flow. Some of the atmospheric effects that degrade the strength of the signal include rain, fog, haze, snow, scintillation etc. As India is a tropical country rainfall plays a prominent role in changing the climate of the place [6][8]. Simultaneously rain also shows similar effect on the signal travelling in free space. So, for tropical countries like India the effect of rain on free space communication link is to be studied in advance before creating a link such that a better-quality communication can be achieved [3][11]. Here the effect of rain on a single channel and a $4 / 4$ channel is studied with the help of simulation and the results generated. The single channel system consists of a single transmitter and a receiver and $4 / 4$ system consists of 4 transmitter and receiver pairs. The schematic of the systems designed for simulating the effect of rain are given as

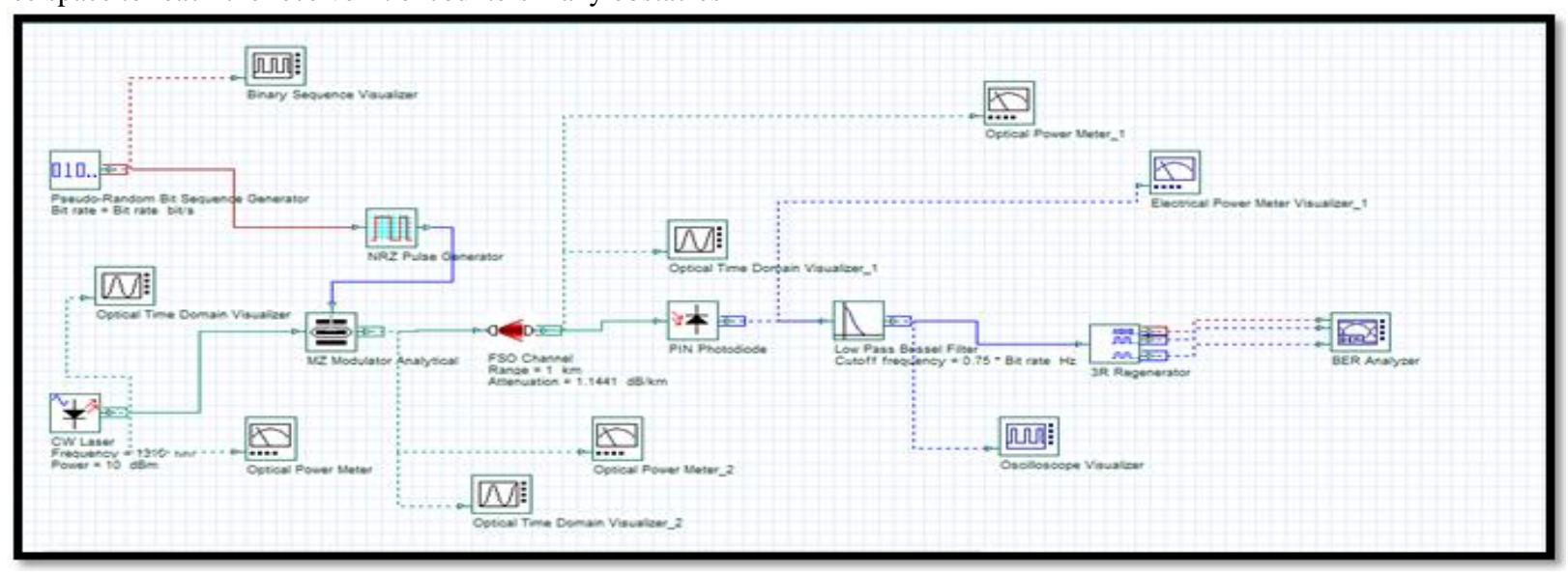

Fig. 1: Single Channel FSO communication system 


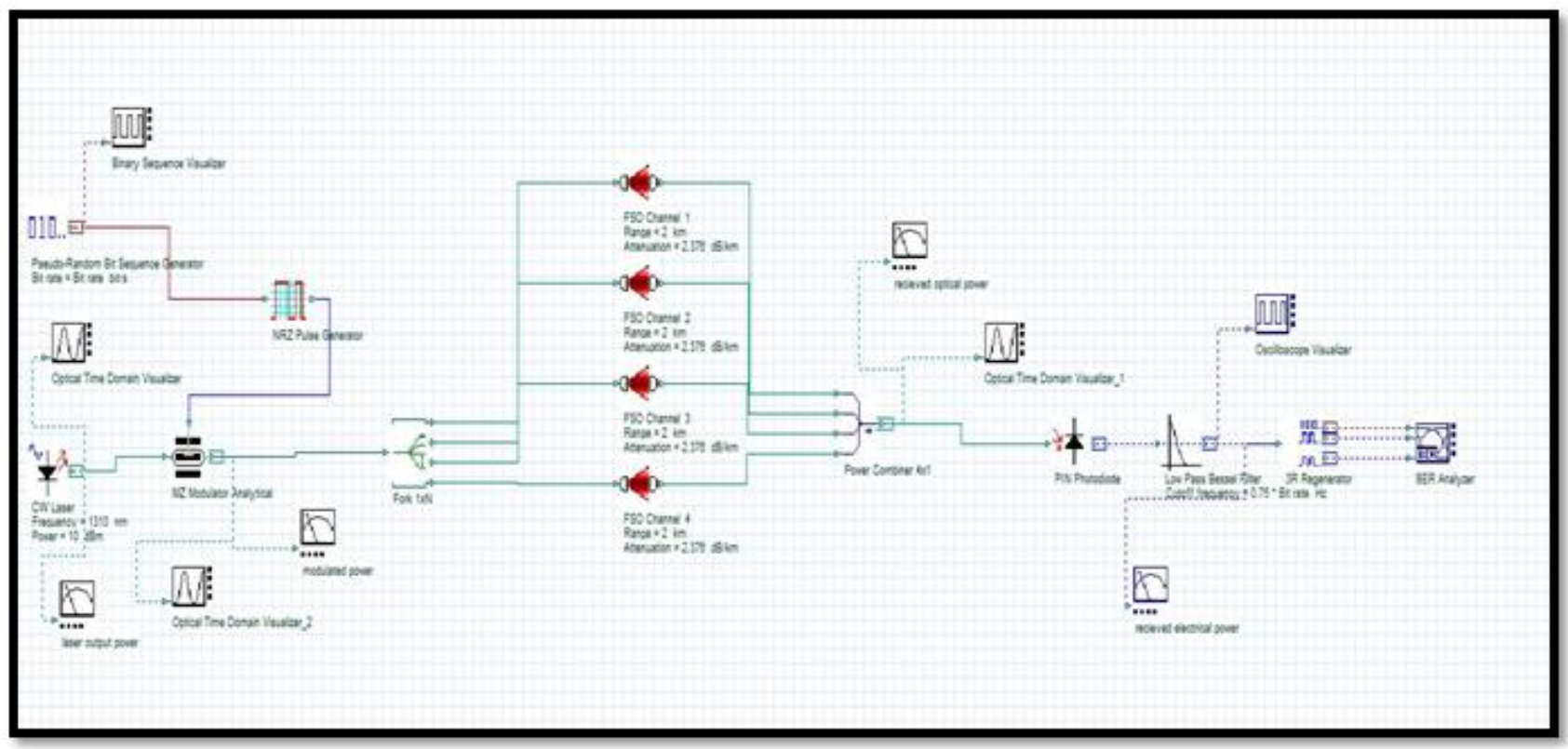

Fig. 2: Four Channel FSO communication system

Both the simulations are designed with a range of $2 \mathrm{~km}$ operation at $1310 \mathrm{~nm}$ and with an input power of $10 \mathrm{dBm}$. The only difference between them is the number of transmitter and receiver pairs [4]. The effect of rain on the two systems that are designed is simulated. As the raw rain data cannot be used for the simulation purpose the corresponding specific attenuation needs to be estimated such that the simulation can be performed [5].

For estimating the specific attenuation due to rain, the raw data which is the rain rate $(\mathrm{mm} / \mathrm{hr})$ is necessary. This data is obtained from the disdrometer recordings and the necessary calculations are performed to obtain the specific attenuation. The specific attenuation calculations done with the help of models like Japan, Carbonneau proposed by ITU-R and the other models like Samir, Suriza developed based on tropical climate.

\section{Specific Attenuation Models}

\subsection{Japan Model}

This model is proposed by the International Telecommunication Union based on the measurements made in Japan. The recommendation R-REC-P.1814 clearly explains the characteristics of the specific attenuation models designed based on the Japan climate [7]. The equation for estimating the specific attenuation due rain using Japan model is given as

where

$$
\gamma_{\text {rain }}=k \cdot R^{\alpha}
$$

$\gamma_{\text {rain }}$-Specific Attenuation due to Rain $\mathrm{dB} / \mathrm{km}$.

$\mathrm{k}, \alpha$ - Power Law Parameters.

R-Rain Intensity $\mathrm{mm} / \mathrm{hr}$.

Here power law parameters are temperature and frequency dependent. The values of $\mathrm{k}$ and $\alpha$ for the Japan model are given as

Table 1: Power law parameters for Japan Model

\begin{tabular}{|c|c|c|}
\hline Location & $\mathrm{k}$ & $\alpha$ \\
\hline Japan & 1.58 & 0.63 \\
\hline
\end{tabular}

\subsection{Carbonneau Model}

The second most famous model for estimating the specific attenuation due to rain recommended by ITU-R is the Carbonneau Model which was developed based on the measurements made in France. The specific attenuation observed due to rain developed by Carbonneau model is given by the equation

where $\gamma_{\text {rain }}$-Specific Attenuation due to Rain $\mathrm{dB} / \mathrm{km}$.

$\mathrm{k}, \alpha$-Power Law Parameters.

R-Rain Intensity $\mathrm{mm} / \mathrm{hr}$.

Here power law parameters are temperature and frequency dependent. The values of $\mathrm{k}$ and $\alpha$ for the Carbonneau model are given as

Table 2: Power law parameters for Carbonneau Model

\begin{tabular}{|c|c|c|}
\hline Location & $\mathrm{k}$ & $\alpha$ \\
\hline France & 1.076 & 0.67 \\
\hline
\end{tabular}

\subsection{Samir Model}

The Samir model was developed based on the tropical climate [10]. The equation for estimating the specific attenuation using Samir's model is given as

where

$$
\gamma_{\text {rain }}=k \cdot R^{\alpha}
$$

$\gamma_{\text {rain }}$-Specific Attenuation due to Rain $\mathrm{dB} / \mathrm{km}$.

$\mathrm{k}, \alpha$ - Power Law Parameters.

R-Rain Intensity in $\mathrm{mm} / \mathrm{hr}$.

Here power law parameters are temperature and frequency dependent. The values of $\mathrm{k}$ and $\alpha$ for the Samir model are given as

Table 3: Power law parameters for Samir Model

\begin{tabular}{|c|c|c|}
\hline Climate & $\mathrm{k}$ & $\alpha$ \\
\hline Tropical & 2.03 & 0.74 \\
\hline
\end{tabular}

\subsection{Suriza Model}

Suriza Model is based on the formulation based on the tropical climate like the Samir model but experimented in a different location. The equation for the Suriza model is given as

$$
\gamma_{\text {rain }}=k \cdot R^{\alpha}
$$

where

$\gamma_{\text {rain }}$-Specific Attenuation due to Rain $\mathrm{dB} / \mathrm{km}$.

$\mathrm{k}, \alpha$ - Power Law Parameters.

R-Rain Intensity $\mathrm{mm} / \mathrm{hr}$.

Here power law parameters are temperature and frequency dependent. The values of $\mathrm{k}$ and $\alpha$ for the Suriza model are given as

Table 4: Power law parameters for Suriza Model

\begin{tabular}{|c|c|c|}
\hline Climate & $\mathrm{k}$ & $\alpha$ \\
\hline Tropical & 0.4195 & 0.8486 \\
\hline
\end{tabular}

Using the four models the specific attenuation was calculated at different rain rates and are incorporated into OptiSystem. Then 
the performance of the systems in the presence of rain is analysed with the help of the results obtained.

Eye diagram is one of the important parameters that describe the behaviour of the communication system [9]. The eye diagrams that are obtained after simulating the rain effect on $1 / 1$ and $4 / 4$ channels which are given in figure 3 and 4.

By observing the eye diagrams of single channel, it is clear that as the rain intensity is increasing the eye opening is getting reduced and at the maximum rain rate the eye is totally closed with a maximum bit error rate of 1 which means that the system is in an outage period.

The eye diagrams of the $4 / 4$ channel system show the efficiency of the system over the single channel one. The eye opening is very much wider in the case of $4 / 4$ system because of the presence of multiple transmitters and receivers.

The multiple transceiver system also followed the same pattern of the single channel system, but the extent of the eye closing is very little. As both the systems are simulated for a $2 \mathrm{~km}$ distance the eye diagrams conclude that a multiple transceiver system perform far better than the single channel systems in the presence of rain avoiding the occurrence of outage period.

\section{Results}

Along with the eye diagrams the other prominent parameters that characterise the system performance are the received optical power, received electrical power and the quality factor. All these parameters are estimated for the designed free space optical communication system and the graphs are generated in both the single and multiple channel systems.

At different rain intensity levels, the values of received optical power are obtained from the simulation and the plots are generated. The variation in the received optical power for a single channel system separated with a $2 \mathrm{~km}$ distance is given in figure 5.

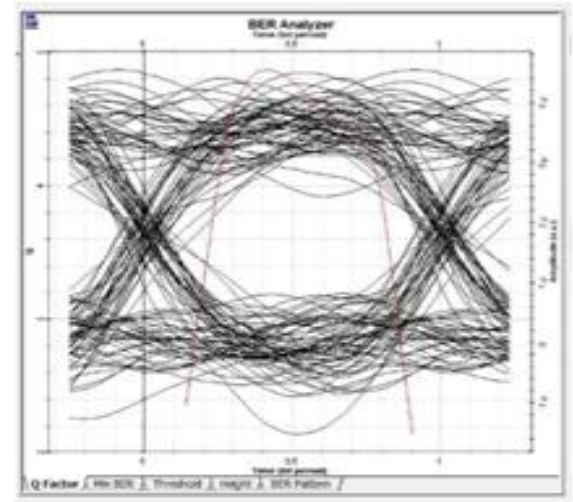

a. $\mathrm{R}=0.583 \mathrm{~mm} / \mathrm{hr}$

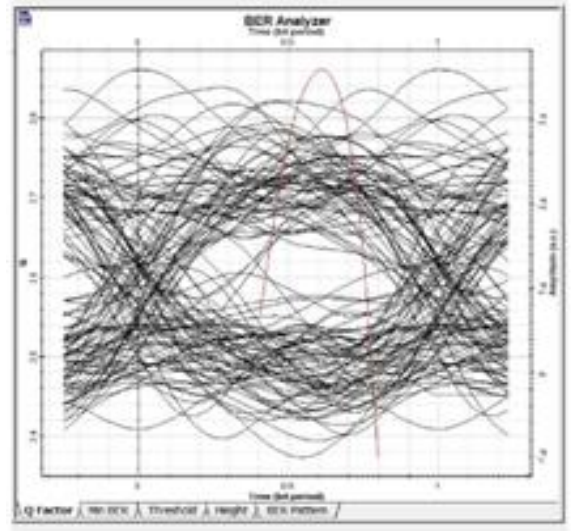

b. $\mathrm{R}=1.668 \mathrm{~mm} / \mathrm{hr}$

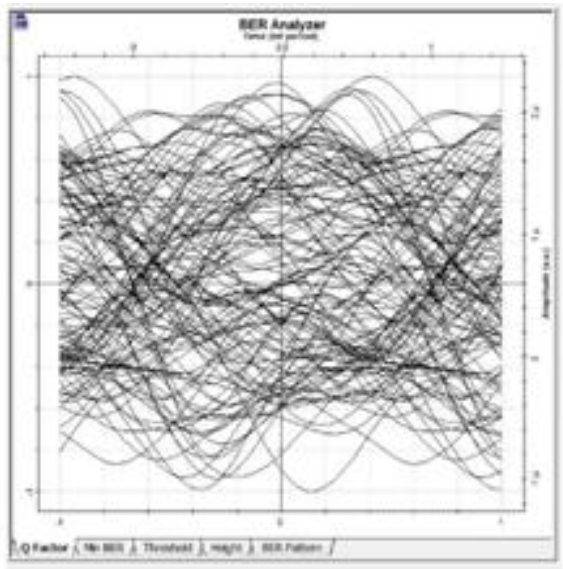

c. $\mathrm{R}=3.262 \mathrm{~mm} / \mathrm{hr}$

Fig. 3: Eye Diagrams of single channel system at different rain rates

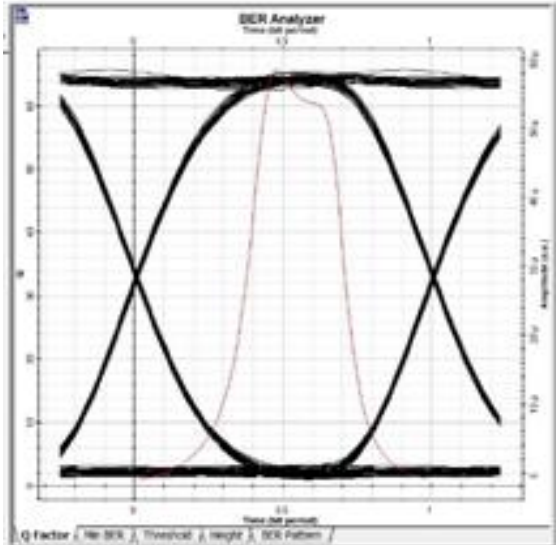

a. $\mathrm{R}=0.583 \mathrm{~mm} / \mathrm{hr}$

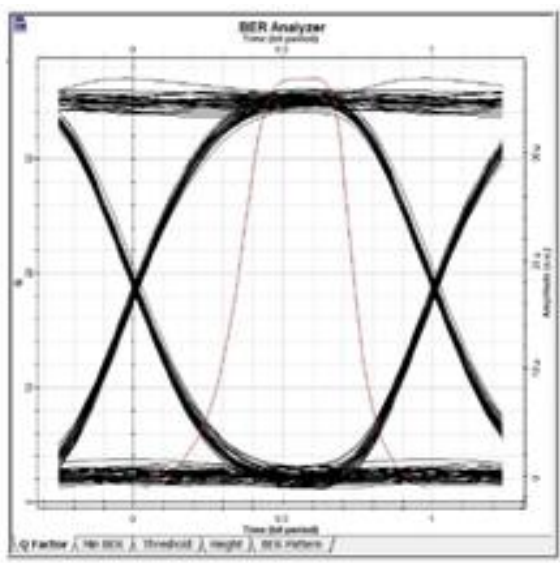

b. $\mathrm{R}=1.668 \mathrm{~mm} / \mathrm{hr}$

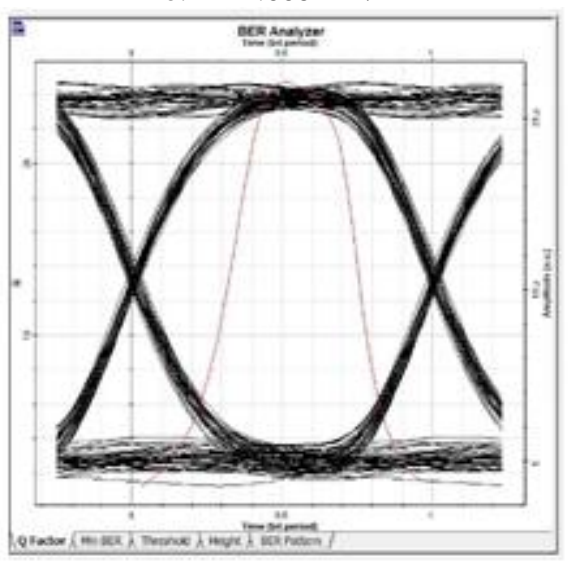

c. $\mathrm{R}=3.262 \mathrm{~mm} / \mathrm{hr}$

Fig. 4: Eye Diagrams of $4 / 4$ channel system at different rain rates 


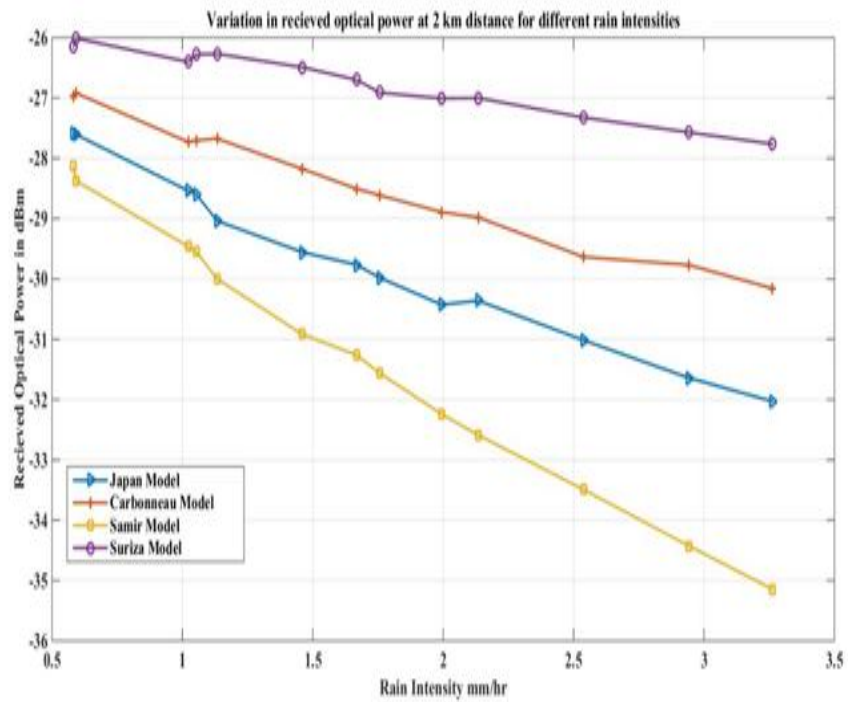

Fig. 5: Variation in received optical power for a single channel system

Here the maximum received power was found to be -26.1493 $\mathrm{dBm}$ for Suriza model which o. The power levels obtained for the other two models lie in between the Samir and Suriza models. The variation in the received optical power in multiple channel case is given as

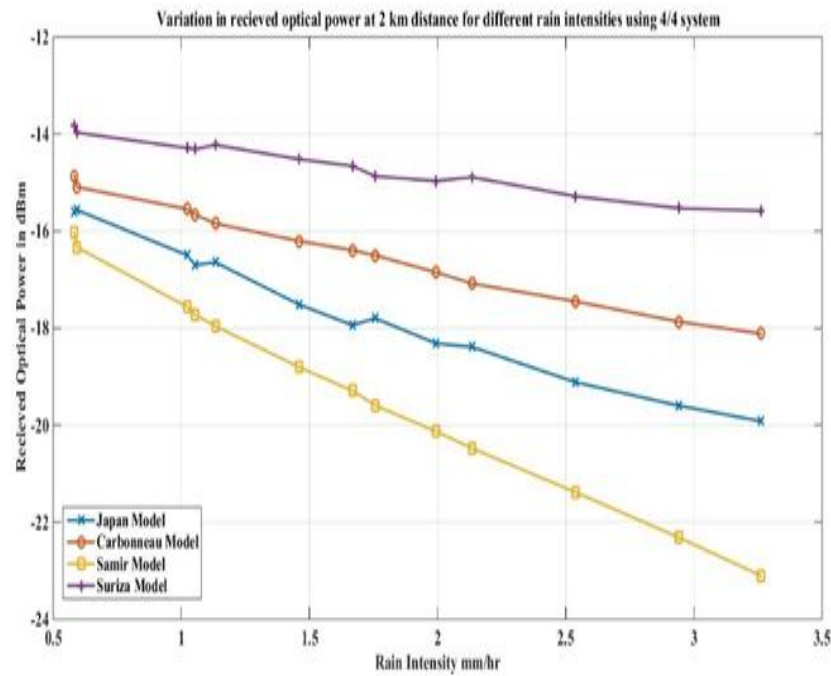

Fig. 6: Variation in received optical power for multiple channel system

The variations in the received optical power for a multiple channel follows a similar pattern with that of the single channel but the received power levels are very much enhanced in the case of the multiple channel system. The highest received optical power was found to be around $-13.8238 \mathrm{dBm}$ which is almost double the power that is captured by the single channel system at the same distance under rainy condition.

The variation in the received electrical power also follows the same pattern of that of the optical power. For the single channel system, the variation is given as

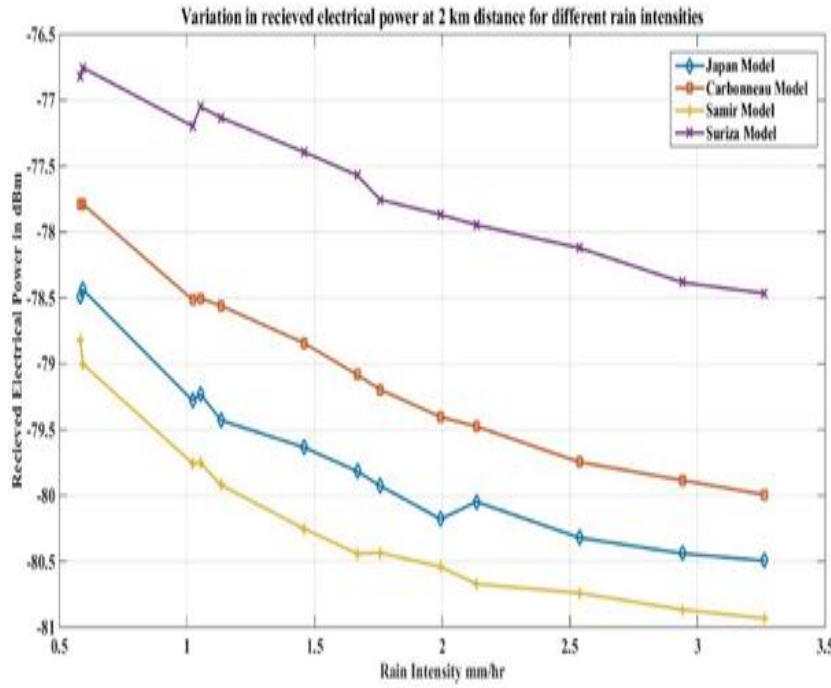

Fig. 7: Variation in received electrical power for single channel system

As all the measurement devices work with electrical power it is necessary to convert the optical signal to electrical and perform analysis. The maximum electrical power was found for the Suriza Model and the lowest power was found for the Samir Model at lower rain rate.

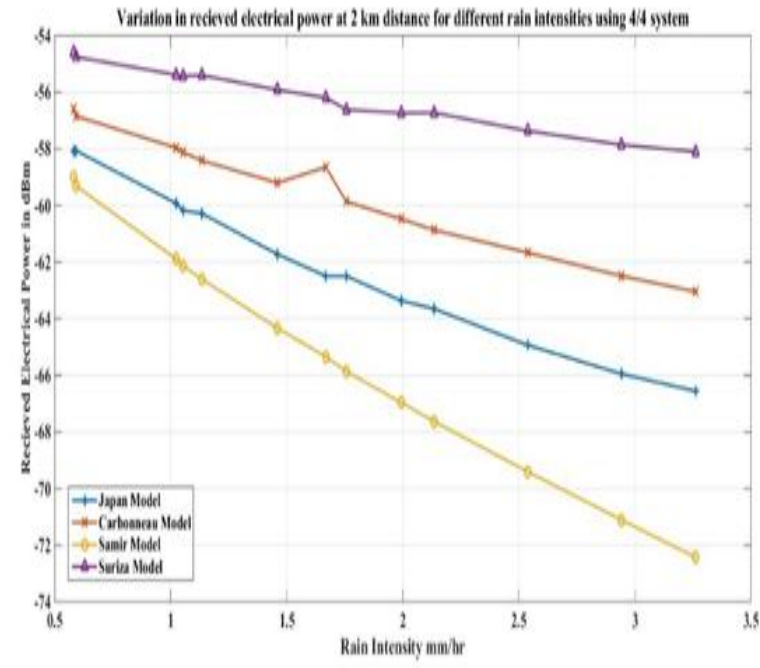

Fig. 8: Variation in received electrical power for multiple channel system

The variation in electrical power followed the same pattern with that of the optical power like high power was observed at low rain intensities and lower at higher rain rates. The maximum power observed was $-54.5983 \mathrm{dBm}$.

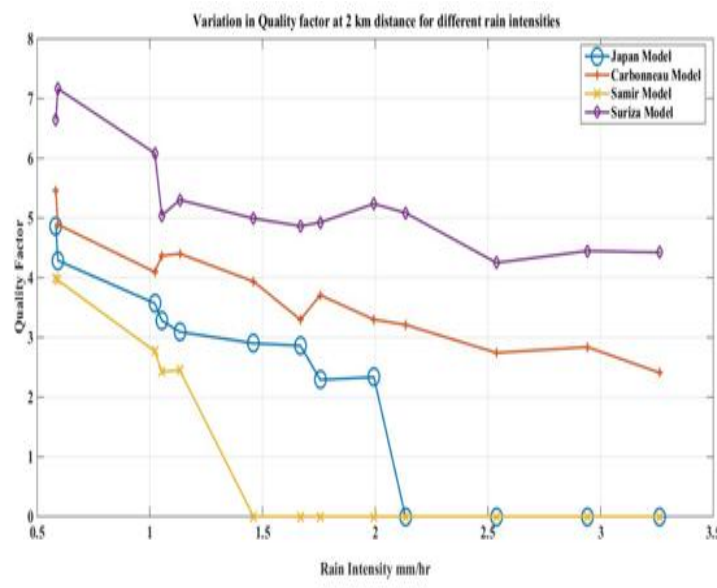

Fig. 9: Variation in Quality Factor for single channel system 
The highest Quality factor was observed for Suriza model at lowest rain rate which is around 7.16. At higher rain rates greater than $1.5 \mathrm{~mm} / \mathrm{hr}$ the system was totally turned off due the intensity of the rain at $2 \mathrm{~km}$ distance.

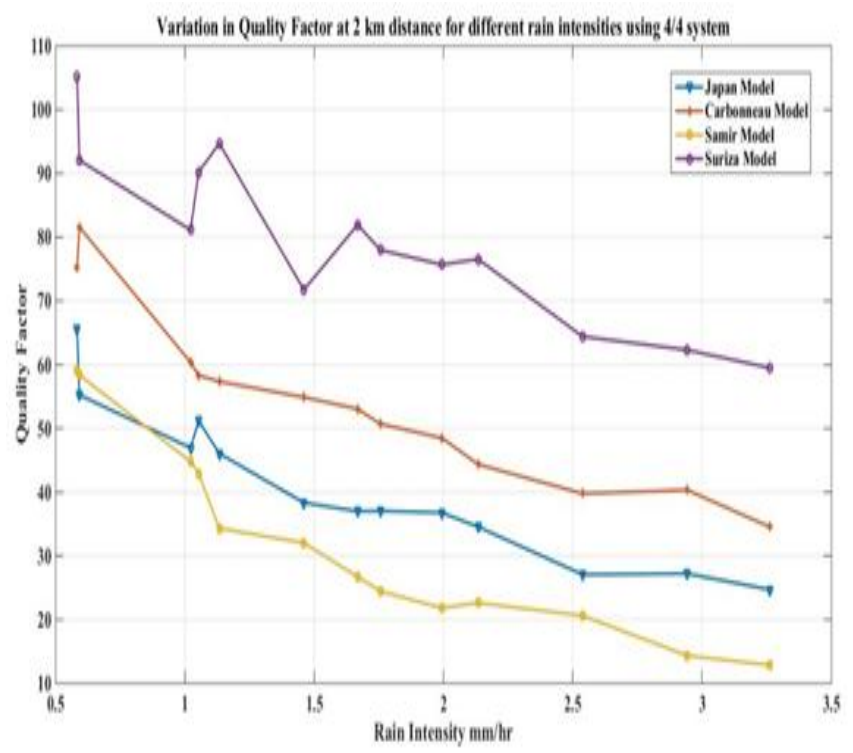

Fig. 10: Variation in Quality Factor for multiple channel system

As the number of channels are more in the above case the quality factor of the system for all the four models raised to a very high value compared to that of a single channel system. This is due to the presence of multiple number of channels.

\section{Conclusion}

The above results conclude that at any rain rate the performance of the multiple channel system is better compared to the single channel system in the view of received power and quality factor. The received optical power was found to be twenty times higher in the case of multiple channel over the single channel system. An increase in the received electrical power was also observed in the case of multiple system which is obvious as it depends on the received optical power. The raised power level was almost like the optical power pattern. The quality factor also showed a huge difference between the single channel and multiple channel system which is greater than double of its value. It can be concluded that multiple channel systems multiple channel systems can perform better than single channel systems when scaled with respect to parameters like electrical and optical powers and also Quality factor even when the system is experiencing turbulence.

\section{References}

[1] Samir A.Al-Gailani,Abu Bakar Mohammad,Usman U.Sheikh, "Determination of rain attenuation parameters for free space optical link in tropical rain",Optik,2014,Vol. 125, Issue 4,15751578.

[2] Nur Haedzerin Md Noor, Ahmed Wathik Naji And Wajdi AlKhateeb, "Performance Analysis of a Free Space Optics Link With Multiple Transmitters/Receivers", IIUM Engineering Journal, 2012, Vol. 13, Issue 1, 49-58.

[3] S.A.Al-Gailani, A.B.Mohammad, R.Q.Shaddad, "Enhancement of free space optical link in heavy rain attenuation using multiple beam concept", Optik, 2013, Vol 124, Issue 21, 4798-4801.

[4] Govardhani.Immadi, Kotamraju, S.K. Venkata Narayana, M.,Khan, H., Sree Madhuri, A., Sravya Chowdary, K., Vineela, P, "Measurement of tropospheric scintillation using $\mathrm{KU}$ band satellite beacon data in tropical region", ARPN Journal of Engineering andApplied Sciences Open Access Volume 10, Issue 4, 2015, Pages 1568-1572.
[5] Govardhani, Immadi., Kotamraju, S.K., Khan, H., Venkata Narayana, M., Hema vasavi, K., Naga Sai, K.P., Sirisha, N.," Estimation of $\mathrm{Ku}$ band satellite signal propagation impairment due to rain in tropical environment using ITU-R", International Journal of Applied Engineering Research, Volume 9, Issue 20, 2014, pages7149-7168.

[6] Scott Bloom,Eric Korevaar, John Schuster, Heinz Willebrand,"Understanding the performance of free-space optics",Journal Of Optical Networking,2003,Vol 2,Issue 6,178200.'

[7] Suriza A.Z., Islam Md. Rafiqul, Wajdi Al-Khateeb And A.W. Naji,"Analysis Of Rain Effects On Terrestrial Free Space Optics Based On Data Measured In Tropical Climate",IIUM Engineering Journal, 2011,Vol. 12, Issue. 5.

[8] Ahmed Basahel, Islam Md.Rafiqul, Mohamad Hadi Habaebi and A. Z. Suriza,"A Proposed Rain Attenuation Prediction Method For Free Space Optical Link Based On Rain Rate Statistics", ARPN Journal of Engineering and Applied Sciences,2015,Vol 10 ,Issue 23,1819-6608,17351-17355.

[9] Govardhani.Immadi, Venkata Narayana M, A.Sree Madhuri, V.L.Tejaswani Sabbasani," Simulation of free space optical communication under different weather conditions", International Journal of Pure and Applied Mathematics",2017,Vol 117,Issue 18,1311-8080, 143-147.

[10] A.Sree Madhuri, Govardhani.Immadi, Venkata Narayana $M$ "Estimation of cumulative distribution of scintillation effect on $\mathrm{Ku}$ band frequencies for one of the tropical regions using various models" ,Journal of Engineering Science and Technology Review,2018,Vol 11,Issue 1, 1791-9320,151-155.

[11] Avinash Yadlapati, Dr. Hari Kishore Kakarla, "An Advanced AXI Protocol Verification using Verilog HDL", Wulfenia Journal, ISSN: 1561-882X, Volume 22, Number 4, pp. 307-314, April 2015

[12] P Ramakrishna, K. Hari Kishore, "Design of Low Power 10GS/s 6-Bit DAC using CMOS Technology "International Journal of Engineering and Technology(UAE), ISSN No: 2227-524X, Vol No: 7, Issue No: 1.5, Page No: 226-229, January 2018.

[13] A Murali, K. Hari Kishore, "Efficient and High Speed Key Independent AES Based Authenticated Encryption Architecture using FPGAs "International Journal of Engineering and Technology(UAE), ISSN No: 2227-524X, Vol No: 7, Issue No: 1.5, Page No: 230-233, January 2018.

[14] G.S.Spandana, K Hari Kishore "A Contemporary Approach For Fault Diagnosis In Testable Reversible Circuits By Employing The CNT Gate Library" International Journal of Pure and Applied Mathematics, ISSN No: 1314-3395, Vol No: 115, Issue No: 7 , Page No: 537-542, September 2017.

[15] K Bindu Bhargavi, K Hari Kishore "Low Power BIST on Memory Interface Logic", International Journal of Applied Engineering Research, ISSN 0973-4562, Volume 10, Number 08 , pp. 2107921090, May 2015.

[16] Nidamanuri Sai Charan, Kakarla Hari Kishore "Reorganization of Delay Faults in Cluster Based FPGA Using BIST" Indian Journal of Science and Technology, ISSN No: 0974-6846, Vol No.9, Issue No.28, page: $1-7$, July 2016.

[17] Sravya Kante, Hari Kishore Kakarla, Avinash Yadlapati,"Design and Verification of AMBA AHB-Lite protocol using Verilog HDL" International Journal of Engineering and Technology, EISSN No: 0975-4024, Vol No.8, Issue No.2, Page:734-741, May 2016. 